\section{Mutações no gene do receptor do fator de crescimento insulina-símile 1 (IGFIR) como causa de retardo do crescimento pré- e pós-natal}

\author{
Mutations in insulin-like growth factor receptor 1 gene (GF1R) \\ resulting in intrauterine and postnatal growth retardation
}

Andréa de Castro Leal', Ana Pinheiro Machado Canton², Luciana Ribeiro Montenegro', Débora Cabral Coutinho', Ivo Jorge Prado Arnhold' ', Alexander Augusto de Lima Jorge ${ }^{2}$

\begin{abstract}
SUMÁRIO
Aproximadamente $10 \%$ das crianças nascidas pequenas para a idade gestacional (PIGs) não apresentam recuperação espontânea do crescimento. As causas desse déficit de crescimento pré-natal e sua manutenção após o nascimento ainda não são completamente conhecidas na maioria dos casos. Nos últimos oito anos, diversas mutações inativadoras e deleções do gene IGF1R em heterozigose foram relatadas, indicando o papel de defeitos no eixo IGFs/IGF1R como causa do déficit de crescimento. Postula-se que pelo menos $2,5 \%$ das crianças nascidas PIGs possam apresentar defeitos no gene IGF1R. O quadro clínico desses pacientes apresenta grande variabilidade quanto à gravidade do retardo de crescimento e aos parâmetros hormonais. Nos casos mais evidentes, os pacientes apresentam microcefalia, déficit cognitivo leve e valores elevados de IGF-1, associados à baixa estatura de início pré-natal. Esta revisão abordará os aspectos clínicos, moleculares e do tratamento da baixa estatura com hrGH de crianças com mutações no IGF1R. Arq Bras Endocrinol Metab. 2011;55(8):541-9
\end{abstract}

\section{Descritores}

Receptor do fator de crescimento insulina-símile 1; mutação; retardo do crescimento intrauterino; transtornos do crescimento; crianças nascidas pequenas para a idade gestacional

\section{SUMMARY}

Approximately $10 \%$ of children born small-for-gestational age (SGA) do not show spontaneous growth catch-up. The causes of this deficit in prenatal growth and its maintenance after birth are not completely known, in most cases. Over the past eight years, several heterozygous inactivating mutations and deletions in IGF1R gene have been reported, indicating the role of defects in the IGFs/IGF1R axis as a cause of growth deficit. It has been hypothesized that at least $2.5 \%$ of children born SGA may have IGF1R gene defects. The clinical presentation of these patients is highly variable in the severity of growth retardation and hormonal parameters. In the most evident cases, patients have microcephaly, mild cognitive impairment and high levels of IGF-1, associated with short stature of prenatal onset. This review will describe the clinical, molecular and treatment of short stature with $\mathrm{hrGH}$ of children with mutations in the IGF1R gene. Arq Bras Endocrinol Metab. 2011;55(8):541-9

Keywords

Insulin-like growth factor I; receptor, IGF type 1; mutation; fetal growth retardation; growth disorders
1 Unidade de Endocrinologia do Desenvolvimento, Laboratório de Hormônios e Genética Molecular LIM/42, Hospital das Clínicas, Disciplina de Endocrinologia, Faculdade de Medicina da Universidade de São Paulo (FMUSP), São Paulo, SP, Brasil 2 Unidade de Endocrinologia Genética, Laboratório de Endocrinologia Celular e Molecular LIM/25, Disciplina de Endocrinologia, Hospital das Clínicas, FMUSP, SP, Brasil

\author{
Correspondência para: \\ Alexander Augusto de Lima Jorge \\ Faculdade de Medicina da USP \\ (LIM-25) \\ Av. Dr. Arnaldo, 455, $5^{\circ}$ andar, sala \\ 5340 \\ 01246-903 - São Paulo, SP, Brasil \\ alexj@usp.brou alexj@pq.cnpq.br \\ Recebido em 15/Out/2011 \\ Aceito em 20/Out/2011
}

\section{INTRODUÇÃO}

proximadamente $20 \%$ das crianças com baixa es-
Ltatura apresentaram deficiência de crescimento intrauterino (RCIU) (1). O termo RCIU refere-se ao crescimento fetal atenuado e frequentemente resulta no nascimento de uma criança pequena para a idade 
gestacional (PIG) $(2,3)$. A maioria das crianças nascidas PIGs apresenta recuperação espontânea do crescimento na vida pós-natal, com normalização da sua estatura ao redor do segundo ano de vida, quer nascidas prematuras ou a termo. Entretanto, $10 \%$ a $15 \%$ de crianças nascidas PIGs permanecem baixas, apresentando $\mathrm{Z}$ da altura inferior a -2 . As causas desse déficit de crescimento pré-natal e sua manutenção após o nascimento ainda não são completamente conhecidas $(1,2,4)$.

A fisiologia do crescimento pré-natal difere consideravelmente daquela do crescimento pós-natal. O hormônio do crescimento ( $\mathrm{GH}$, growthhormone) e o fator de crescimento insulina-símile tipo l (IGF-1, insulin-likegrowthfactor 1) compõem o principal sistema endócrino regulador do crescimento linear durante a infância. Entretanto, na vida pré-natal, o GH exerce pouco efeito sobre o crescimento fetal (5). Nessa fase, o IGF- 1 e o fator de crescimento insulina-símile tipo 2 (IGF-2, insulin-likegrowthfactor 2), de maneira independente da secreção de $\mathrm{GH}$, são os principais fatores endócrinos determinantes do crescimento. Os efeitos biológicos desses IGFs são mediados pelo receptor de IGF tipo 1 (IGF-1R) durante todas as fases da vida (6).

$\mathrm{O}$ envolvimento do sistema IGFs/IGF-1R como causa genética da baixa estatura em crianças nascidas PIGs foi comprovado em 1996 por Woods e cols., que descreveram o primeiro paciente com defeito no gene $I G F 1$, o qual apresentava deleção em homozigose dos éxons 4 e 5 desse gene (5). Posteriormente em 2003, Bonapace e cols. descreveram um paciente que apresentava uma troca de $\mathrm{T} \rightarrow \mathrm{A}$ na região $3^{\prime}$ não traduzida do éxon 6 do IGFI (região reguladora do processo de poliadenilação) (7), porém essa alteração foi identificada por Coutinho e cols. em indivíduos controles (8). Já em 2005, Walenkamp e cols. identificaram uma mutação homozigota que causa a troca do aminoácido valina por metionina na posição 92 da proteína do IGF-1 (c.274 $\mathrm{G}>\mathrm{A}, \mathrm{p} . \mathrm{V} 92 \mathrm{M})$, levando à formação de uma molécula biologicamente inativa (9). Recentemente, foi descrita mutação homozigota missense que causa a troca do aminoácido arginina por glutamina na posição 84 (c.25l $\mathrm{G}>\mathrm{A}, \mathrm{p} . \mathrm{R} 84 \mathrm{Q}$ ), ocasionando prejuízo da atividade mitogênica do IGF-1 e de sua ligação ao receptor IGF-1R (10). Dos quatro pacientes descritos, três apresentavam características comuns: baixo peso e comprimento ao nascimento, baixa estatura importante na idade adulta, microcefalia, micrognatia, surdez neurossensorial e atraso de desenvolvimento neuropsicomotor (DNPM). O quarto paciente apresentava quadro clínico menos grave.
Laboratorialmente, apresentavam valores normais ou elevados de GH, com concentrações de IGF-I indetectáveis nos casos de mutações que causavam deficiência de IGF-l ou elevado no caso do paciente com IGF-1 biologicamente inativo. Apesar dessas descrições isoladas, defeitos no IGF-1 são uma causa rara de RCIU (8).

Em contraste, mutações inativadoras e deleções do gene do IGFIR em heterozigose vêm sendo relatadas de forma crescente nos últimos oito anos em pacientes com história de déficit de crescimento pré- e pós-natal (11-18). Postula-se que pelo menos $2 \%$ a $3 \%$ das crianças nascidas PIGs poderiam apresentar defeitos no IGFIR (12). O quadro clínico desses pacientes apresenta grande variabilidade quanto à gravidade do retardo de crescimento pré- e pós-natal e aos parâmetros hormonais. Esta revisão abordará os aspectos clínicos, moleculares e do tratamento da baixa estatura com hrGH de crianças por mutações no IGFIR.

\section{RECEPTOR 1 DA IGF (IGF1R) - DO GENE À PROTEÍNA}

O IGF-1R humano é codificado por um único gene (IGFIR, NM_147370) com tamanho de 307 quilobases e organizados em 21 éxons, localizado na região distal do braço longo do cromossomo 15 , posição 25 26 (15q25-26) (19). Possui um único sítio de início de transcrição. Os éxons 1 a 11 codificam a região 5' não traduzida, o peptídeo sinal e a subunidade $\alpha$, enquanto os éxons 12 a 21 codificam a subunidade $\beta$ do IGFIR (Figura 1). O éxon 14 codifica a porção transmembrânica do receptor, enquanto os éxons 16 a 21 codificam o domínio tirosina-quinase intracelular. $\mathrm{O}$ final do éxon 21 codifica ainda a região 3' não traduzida. O sítio de clivagem é codificado pelo éxon 11 e nessa região o pró-IGF-1R é clivado em subunidades $\alpha$ e $\beta$ (Figura 1). O IGFIR possui dois transcritos resultantes de um "splice" alternativo no éxon 14 (região codificadora da porção extracelular da subunidade $\beta$ ): o primeiro transcrito corresponde à sequência íntegra de $\mathrm{cDNA} e$ o segundo difere do primeiro pela perda de três nucleotídeos (CAG) a partir da posição 2829 do cDNA (19).

O IGF-1R é sintetizado como um peptídeo de cadeia única (pré-pró-receptor), contendo os 30 resíduos do peptídeo sinal e o sítio de clivagem $\left(\operatorname{Arg}_{708}\right.$ - $\left.\mathrm{Lys}_{709}-\operatorname{Arg}_{710}-\operatorname{Arg}_{711}\right)$. Durante sua transferência para o retículo endoplasmático, ocorre a retirada dos 30 resíduos do peptídeo sinal formando o pró-IGF-1R. Os monômeros de pró-receptor sofrem modifica- 
ções pós-traducionais com o adequado enovelamento da proteína, formação de pontes dissulfídicas e, após a aminoglicosilação, são transportados para o complexo de Golgi. No interior dessa organela, a maturação do pró-receptor é completada por glicosilação terminal e clivagem do pró-receptor pela protease Furina, resultando na glicoproteína heterotetramérica $\alpha 2 \beta 2$ madura (20). Todo esse processo é essencial para que o receptor maduro possa ser transportado à superfície celular para exercer suas funções biológicas.

O IGF-1R é uma glicoproteína transmembrânica que se liga com maior afinidade ao IGF-1 e com menor afinidade ao IGF-2 e à insulina. Estruturalmente, é semelhante ao receptor de insulina com aproximadamente $50 \%$ de homologia na sequência de aminoácidos. Ambos são receptores tirosina-quinase com- postos de duas subunidades $\alpha$ extracelulares, contendo um sítio de ligação ao ligante e duas subunidades $\beta$ intracelulares com atividade tirosina-quinase intrínseca (21). Enquanto o receptor de insulina confere preferencialmente sinalização que mantém a homeostase metabólica, o IGF-1R tem seu principal papel na regulação da proliferação, diferenciação e apoptose celular, regulando, dessa forma, o crescimento longitudinal e do organismo.

A ligação do IGF- 1 ao seu receptor promove a ativação da sua atividade tirosino-quinase intrínseca, resultando na autofosforilação em sítios de tirosina. Por sua vez, as tirosinas fosforiladas (pY) servem como sítios acopladores de proteínas intracitoplasmáticas que contêm domínios de reconhecimento dessas pY, conhecidos como domínios SH2 (Figura 2). A

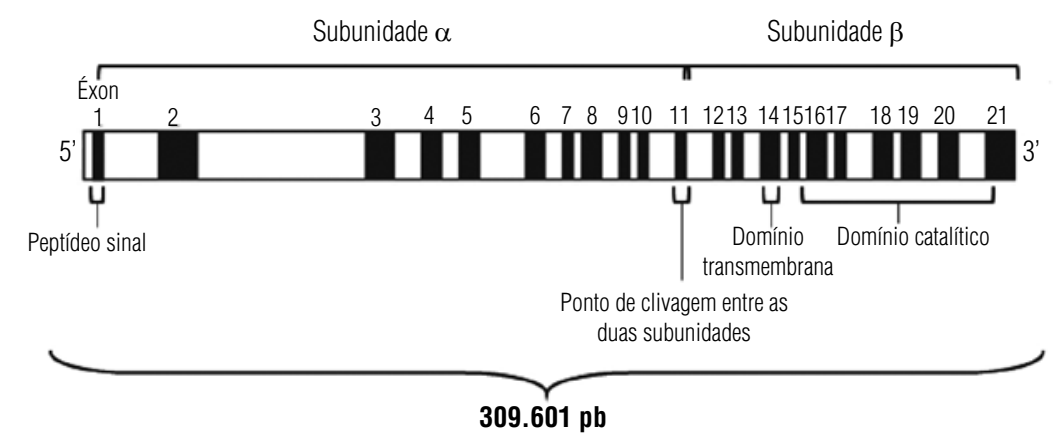

Figura 1. Estrutura do IGF1R. Os éxons são representados pelas barras preenchidas.

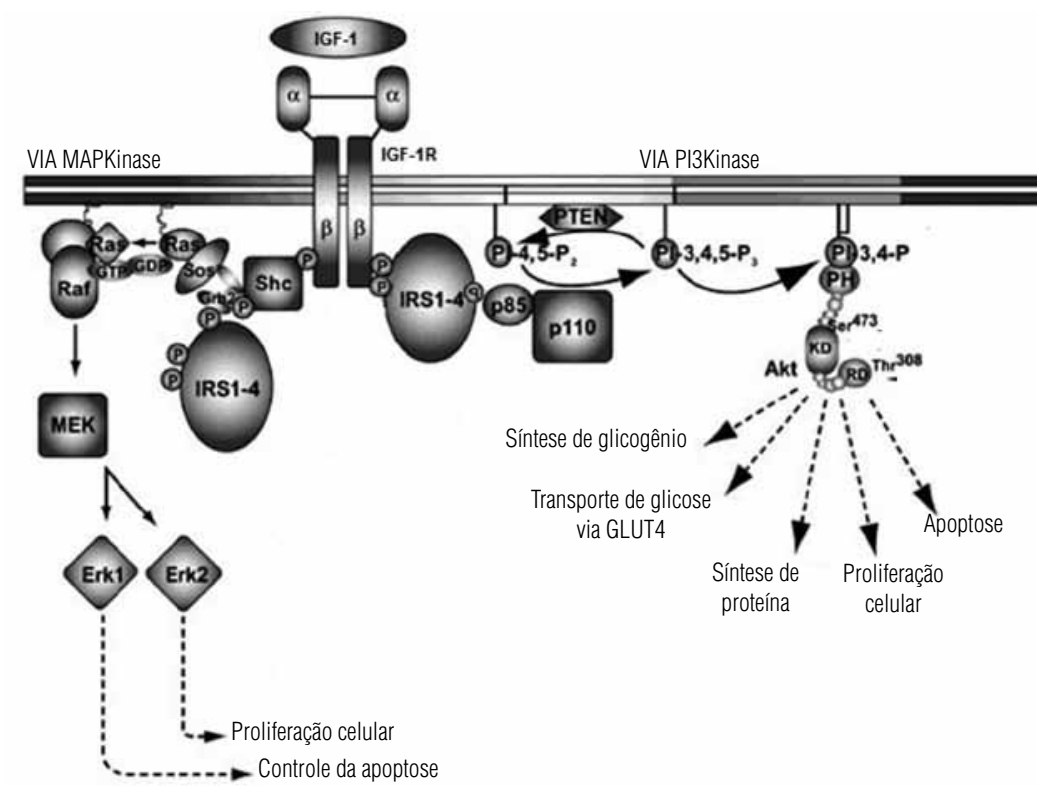

Figura 2. Transdução do sinal do fator de crescimento semelhanteà insulina(IGF-1). MAPK: Ras/Raf/mitogen-activatedprotein kinase; PI3K: phosphatidylinositol 3 kinase; ERK: extracellular signal-regulated kinase; AKT: V-akt murine thymoma viral oncogene homolog; JNK: Jun kinase; GDP: guanosine diphosphate; GTP: guanosine triphosphate; IRS: insulin receptor substrate; MEK: mitogen extracellular kinase; PDK: phosphoinositide-dependent kinase; PH: pleckstrin homology domain; PI: phosphatidylinositol; PTEN: phosphatase and tensin homologue deleted on chromosome 10; SHC: Src homology collagen; SHP: Src homology phosphatase; Grb2: growth fator receptor-bound protein 2; SOS 1: son of sevenless 1; RAF: murine sarcoma viral oncogene homolog; RAS: rat sarcoma viral oncogene homolog; p85 e p110: subunidades 85 e 110 da phosphatidylinositol 3 kinase [adaptado de Dupont and LeRoith (23)]. 
principal proteína ativada pelo IGF-1R é o substrato 1 do receptor de insulina (IRS-1, insulin receptor substrate 1), uma fosfoproteína hidrofílica que pode recrutar e regular a atividade de outras proteínas intracelulares. A IRS-1 funciona como uma molécula adaptadora, ativando cascatas de sinalização associadas a receptores tirosina-quinases. Uma das principais vias de sinalização do IGF-1R é a via denominada proteína quinase ativada por mitógeno (MAPK, mitogen-activated protein kinase), responsável principalmente pelos efeitos proliferativos das IGFs (22). Outra via de sinalização do IGF-1R ocorre por ativação da fosfatidilinositol 3-quinase (PI-3K, phosphatidylinositol 3-kinase), responsável pelos principais efeitos metabólicos estimulados pelas IGFs, como a captação de glicose via GLUT4 e a síntese de glicogênio, efeitos idênticos aos promovidos pela insulina ao se ligar ao seu receptor $(23)$.

\section{MODELOS ANIMAIS DE DEFEITOS NO SISTEMA IGFS/IGF1R}

Nos últimos 13 anos, uma série de experimentos com animais transgênicos identificou a importância do IGF-1, IGF-2, da insulina e de seus respectivos receptores na regulação do crescimento fetal (Tabela 1). Tanto o nocaute em homozigo separa IgfI como para Igf 2 determinaram importante retardo de crescimento intrauterino (redução de $40 \%$ do peso em relação ao controle), mostrando a importância desses dois hormônios no crescimento fetal $(24,25)$. O nocaute duplo do $I g f I+I g f 2$ ocasionou déficit de crescimento mais grave e semelhante ao nocaute em homozigose do Igflr (redução de $70 \%$ do peso no nascimento). Porém, os animais nocautes homozigotos para o Igflr morreram logo após o nascimento por insuficiência respiratória. Por sua vez, os animais nocautes heterozigotos para o Igflr são fenotipicamente normais no nascimento. O nocaute do IgfI ou Igf2, associado ao nocaute do Igflr, não se diferenciou do nocaute isolado IgfIr, sugerindo a ação predominante desses dois hormônios por meio do IGF-1R na determinação do crescimento fetal (24). Os animais apresentavam, além do RCIU, alta mortalidade perinatal por problemas respiratórios e hipoplasia de diversos órgãos (SNC, pele, músculo e esqueleto). Nocautes de outros hormônios e receptores (como insulina e $\mathrm{GH}$ ) influíram de forma menos expressivas no desenvolvimento pré-natal (26).
Tabela 1. Fenótipo em relação ao crescimento pré-natal de diversos modelos animais com nocaute em diversos genes

\begin{tabular}{lcc}
\hline Gene deletado & $\begin{array}{c}\text { \% do peso no } \\
\text { nascimento em } \\
\text { relação ao controle }\end{array}$ & Referência \\
\hline Igf1 & 60 & $(24,25)$ \\
Igf2 & 60 & $(27)$ \\
Igf1/Igf2 & 30 & $(24)$ \\
Igf-1R & 45 & $(24)$ \\
Igf1/IGF-1R & 45 & $(24)$ \\
Igf2/IGF-1R & 45 & $(24)$ \\
Insulina & 78 & $(28)$ \\
Ir & 78 & $(26,29,30)$ \\
Ghr & 83 & $(31)$ \\
\hline
\end{tabular}

p: paterno.

\section{MUTAÇÕES NO GENE DO IGF1R}

As primeiras mutações no gene IGFIR foram descritas em 2003 por Abuzzahab e cols. Nestes últimos oito anos, nove famílias (28 indivíduos) foram identificadas com mutações nesse gene. Desses 28 indivíduos, 10 apresentavam mutação nonsense e 18 apresentam mutações missense, quase todas em heterozigose simples, excetuando um único paciente heterozigoto composto para duas mutações missense (Tabela 2). Além dessas mutações de ponto, diversos relatos de pacientes com deleções completas do IGFIR, algumas secundárias a aberrações cromossômicas, foram descritos nesse período (12).

Foram duas as mutações descritas por Abuzzahab e cols. (11). A primeira em heterozigose composta no éxon 2, com a troca de arginina por glutamina no aminoácido 138 (p.Rl38Q) e troca de lisina por asparagina no aminoácido 145 (p.Kl45N). Em conjunto, essas alterações levaram a menor afinidade de ligação do IGF-1 pelo IGF-1R, causando redução na ativação do receptor. A segunda mutação era em heterozigose simples no éxon 2, com a troca de arginina por um códon de parada prematura (stop codon) no aminoácido 89 (p.R89X), ocasionando proteína truncada sem função $(11,15)$.

Em 2005, Kawashima e cols. descreveram mutação em heterozigose no éxon 11 do IGFIR, havendo troca de arginina por glutamina no aminoácido 739 (p.R739Q) (14). Essa alteração leva à diminuição do processamento do pro IGF-1R para IGF-1R por alterar o sítio de clivagem. A mutação p.R511Q, descrita por Inagaki e cols. em 2007, resulta na troca da arginina por glutamina no códon 511 da proteína (13). Esse resíduo corresponde ao domínio N-terminal da fibronectina tipo III do IGF-1R e está localizado próximo à 
primeira ponte dissulfídica entre as duas subunidades $\alpha$. Os estudos funcionais dessas mutações demonstraram que não havia prejuízo na afinidade do receptor pelo IGF-1, mas foi evidenciada diminuição da autofosforilação do IGF-1R mutado e da síntese de DNA estimulada pelo IGF-1 nas linhagens de fibroblastos obtidos dos pacientes com as mutações. Essas evidências corroboram a hipótese de que a alteração conformacional e na estrutura do receptor prejudica a transdução do sinal após sua ligação ao IGF-1.

Walenkamp e cols. descreveram mutação no éxon 16 do gene IGFIR em 2006, levando a troca de ácido glutâmico por lisina na posição 1050 da proteína
(p.E1050K) (13). A mutação p.Gl155A foi descrita por Kruis e cols. em 2010 e encontra-se localizada no éxon 19, havendo troca da glicina pela alanina no códon 1155 (32). Ambas as mutações ocorrem no resíduo de aminoácido altamente conservado, localizado no domínio tirosina-quinase intracelular, ocasionando menor autofosforilação do receptor mutado e, consequentemente, redução na ativação de ERK (pela via MAPK) e AKT (pela via PI3K); porém a expressão do IGF-IR e sua afinidade ao ligante não ficaram comprometidas.

Wallborn e cols. em 2010 descreveram mutação do gene IGFIR levando à troca de timina por adenina na posição 1886, resultando na mudança do aminoácido

Tabela 2. Dados clínicos e laboratoriais das sete famílias com mutação heterozigota do IGF1R

\begin{tabular}{|c|c|c|c|c|c|c|c|c|c|c|c|}
\hline \multirow[b]{2}{*}{ Família } & \multirow[b]{2}{*}{ Paciente } & \multirow[b]{2}{*}{ Mutação } & \multicolumn{2}{|c|}{ Ao nascimento } & \multirow[b]{2}{*}{ Microcefalia } & \multirow[b]{2}{*}{$\begin{array}{c}\text { Atraso } \\
\text { no DNPM }\end{array}$} & \multirow[b]{2}{*}{$\begin{array}{l}\mathrm{Z} \text { de } \\
\text { altura }\end{array}$} & \multicolumn{3}{|c|}{ Avaliação hormonal } & \multirow[b]{2}{*}{ Referência } \\
\hline & & & $Z$ do peso & $\begin{array}{c}\mathrm{Z} \text { do } \\
\text { comprimento }\end{array}$ & & & & IGF-1 & IGFBP-3 & $\begin{array}{c}\text { Pico } \\
\text { deGH } \\
(\mu \mathrm{g} / \mathrm{L})\end{array}$ & \\
\hline $1 \mathrm{~A}$ & Índice & p.R138Q/K145N & $-3,5$ & N.D. & N.D. & Sim & $-4.8^{1}$ & Normal & Elevado & 51 & (11) \\
\hline $1 \mathrm{~B}$ & Mãe & p.K145N & $-2,0$ & N.D. & N.D. & N.D. & $-1.6^{2}$ & N.D. & N.D. & N.D. & (11) \\
\hline $1 \mathrm{C}$ & Pai & p.R138Q & $-2,0$ & N.D. & N.D. & N.D. & $-2.8^{2}$ & N.D. & N.D. & N.D. & (11) \\
\hline $2 A$ & Índice & p.R89X & $-3,5$ & -5.8 & $\operatorname{Sim}$ & $\operatorname{Sim}$ & $-2.6^{1}$ & Normal & Normal & 5.7 & $(11,15)$ \\
\hline $2 B$ & Irmão & p.R89X & $-2,7$ & -2.1 & Sim & Sim & $-3,2^{1}$ & Normal & Normal & 9.8 & $(11,15)$ \\
\hline $2 C$ & Mãe & p.R89X & $-2,6$ & -1.6 & Não & N.D. & $-2.6^{2}$ & Normal & N.D. & N.D. & $(11,15)$ \\
\hline $3 \mathrm{~A}$ & Índice & p.R739Q & $-1,5$ & -1.0 & N.D. & $\operatorname{Sim}$ & $-2.1^{1}$ & Normal & Normal & N.D. & (14) \\
\hline $3 B$ & Mãe & p.R739Q & $-1,6$ & N.D. & N.D. & N.D. & $-2.9^{2}$ & Normal & Normal & N.D. & (14) \\
\hline $4 \mathrm{~A}$ & Mãe & p.E1050K & $-2,1$ & -0.3 & Sim & Não & $-4.0^{2}$ & Normal & Normal & 20 & (16) \\
\hline $4 \mathrm{~B}$ & Filha & p.E1050K & $-3,3$ & -4.2 & Sim & Sim & $-2.3^{1}$ & Elevado & Normal & 74 & (16) \\
\hline $5 A$ & Índice & p.R511Q & $-4,9$ & -3.1 & N.D. & Não & $-5,0^{1}$ & Elevado & Elevado & 10.6 & (13) \\
\hline $5 B$ & Tia & p.R511Q & N.D. & N.D. & N.D. & Não & $-5.0^{2}$ & N.D. & N.D. & N.D. & (13) \\
\hline $6 \mathrm{~A}$ & Índice & p.G1155A & $-1,8$ & -1.8 & Sim & Não & $-3.3^{1}$ & Normal & Normal & 21 & (32) \\
\hline $6 B$ & Irmão & p.G1155A & $-1,9$ & N.D. & Não & N.D. & $-2.3^{1}$ & N.D. & N.D. & N.D. & (32) \\
\hline $6 C$ & Mãe & p.G1155A & N.D. & N.D. & N.D. & N.D. & $-3.9^{2}$ & N.D. & N.D. & N.D. & (32) \\
\hline $6 \mathrm{D}$ & Tio & p.G1155A & $-2,2$ & -1.4 & Não & N.D. & $-1.6^{1}$ & N.D. & N.D. & N.D. & (32) \\
\hline $6 \mathrm{E}$ & Avô & p.G1155A & N.D. & N.D. & N.D. & N.D. & $-2.8^{2}$ & N.D. & N.D. & N.D. & (32) \\
\hline $6 \mathrm{~F}$ & Prima & p.G1155A & N.D. & N.D. & N.D. & N.D. & $-2.8^{2}$ & N.D. & N.D. & N.D. & (32) \\
\hline $6 G$ & Prima & p.G1155A & N.D. & N.D. & N.D. & N.D. & $-2.5^{2}$ & N.D. & N.D. & N.D. & (32) \\
\hline $7 \mathrm{~A}$ & Índice & p.V629E & $-2,2$ & -1.8 & Sim & Sim & $-2.1^{1}$ & Elevado & Normal & N.D. & (33) \\
\hline $7 \mathrm{~B}$ & Mãe & p.V629E & $-2,2$ & -2.3 & Sim & N.D. & $-3.3^{2}$ & N.D. & N.D. & N.D. & (33) \\
\hline $8 \mathrm{~A}$ & Índice & c.3348_3366 dup19 & $-2,2$ & $-0,63$ & Sim & Não & $-3,6^{1}$ & Normal & Normal & 9,1 & (34) \\
\hline $8 B$ & Mãe & c.3348_3366 dup19 & N.D. & N.D. & N.D. & N.D. & $-4,6^{2}$ & N.D. & N.D. & N.D. & (34) \\
\hline $8 \mathrm{C}$ & Irmã & c.3348_3366 dup19 & $-3,8$ & N.D. & N.D. & N.D. & $-1,9^{1}$ & N.D. & N.D. & N.D. & (34) \\
\hline $9 \mathrm{~A}$ & Índice & p.Y387X & $-2,0$ & $-3,1$ & Não & Não & $-4,9^{2}$ & $+1,0$ & N.D. & N.D. & (35) \\
\hline $9 \mathrm{~B}$ & Irmã & p.Y387X & $-1,7$ & $-2,9$ & N.D. & Não & $-1,8^{2}$ & $+1,1$ & N.D. & N.D. & (35) \\
\hline $9 \mathrm{C}$ & Tia paterna & p.Y387X & $-1,9$ & $-1,8$ & N.D. & Não & $-2,8^{2}$ & $-0,9$ & N.D. & N.D. & (35) \\
\hline $9 \mathrm{D}$ & Tia paterna & p.Y387X & $-2,4$ & $-2,3$ & N.D. & Não & $-3,2^{2}$ & $+0,2$ & N.D. & N.D. & (35) \\
\hline
\end{tabular}

N.D.: não disponível. ${ }^{1}$ : na infância. ${ }^{2}$ : na vida adulta. 
valina pelo ácido glutâmico no códon 629 da proteína (p.V629E) (33). Por meio de estudos funcionais, demonstrou-se importante prejuízo na fosforilação do IGF-1R, na via de sinalização da PI3K e na expressão do IGF-1R na superfície celular. Foi observado também acúmulo do pró-IGF-lR no retículo endoplasmático. Com base nesses achados, pode-se afirmar que essa mutação interfere no tráfego do IGF-1R e, consequentemente, compromete o processamento de seu pró-receptor e sua localização na superfície celular.

Fang e cols. descreveram duplicação de 19 nucleotídeos em heterozigose no éxon 18 do IGFIR, ocasionando a mudança no código de leitura (frameshift) e formação de códon de parada em um alelo (34). A mais recente mutação encontrada foi descrita por Mohn e cols., tratando-se de troca de timina por adenina em heterozigose na posição 1161, resultando na formação do códon de parada na posição 387 (p.Y387X) (35). O receptor truncado não possui os domínios de fibronectina tanto na subunidade $\alpha$ quanto na $\beta$, levando à perda de sua ancoragem na membrana plasmática. Essas mutações resultam na diminuição da proteína IGF-1R e consequente diminuição da ativação da via de sinalização do IGF-1R por meio do mecanismo de decaimento do RNA mensageiro (nonsense-mediated $m R N A$ decay) (35).

Em resumo, todas as mutações demonstraram diminuição substancial na autofosforilação da subunidade $\beta$ do IGF-lR acompanhado por uma redução na ativação de pelo menos uma das duas grandes vias de sinalização, fornecendo evidências moleculares adicionais para uma deficiente resposta celular ao IGF-1. Para alguns casos, esses resultados foram reforçados por estudos funcionais, que demonstraram diminuição da proliferação de fibroblastos dos pacientes. Além do fenômeno de haploinsuficiência, algumas mutações do IGFIR podem apresentar efeito dominante negativo, apesar de que esse mecanismo ainda não foi completamente caracterizado nos estudos existentes (36).

\section{CARACTERÍSTICAS FENOTÍPICAS E CLÍNICAS DOS CARREADORES DAS MUTAÇÕES NO IGF-1R}

Todos os pacientes com a mutação no IGFIR apresentavam peso e/ou comprimento de nascimento abaixo do normal ou no limite inferior da normalidade (Tabela 2), observando-se segregação das mutações com o fenótipo de baixa estatura nas várias famílias estudadas. Além disso, a estatura na infância e idade adulta apresentou grande variabilidade entre os casos descritos, mesmo dentro da mesma família (Tabela 2). Nas crianças foi observado em praticamente todos os casos atraso na idade óssea ao redor de $\mathrm{l}$ ano em relação à idade cronológica. A puberdade atrasada foi descrita em três pacientes do sexo feminino $(16,32)$, porém muitos estudos não caracterizaram adequadamente o desenvolvimento puberal. Pacientes com deficiência primária de IGF-1 (33) ou com deficiência de subunidade ácido-lábil (37), que cursam com baixos valores circulantes de IGF-1, também apresentam atraso puberal, sugerindo o papel desse hormônio no mecanismo que regula o início da puberdade.

A microcefalia pode ser considerada como a segunda característica mais comum da resistência ao IGF-1, presente em $67 \%$ dos casos avaliados, indicando a importância do sistema IGF-1/IGF-1R no desenvolvimento do sistema nervoso central (38). Porém, o comprometimento cognitivo é muito variável. Ao contrário dos indivíduos com mutações no gene IGFl, o comprometimento no DNPM é discreto e não foi descrita surdez neurossensorial em nenhum dos pacientes com defeito no $\operatorname{IGFIR}(5,12)$. A presença de coeficiente de inteligência (QI) abaixo da média e retardo da fala foi bem caracterizada em seis casos $(30 \%)$ de mutação heterozigota do IGFIR $(11,14-16,32,35)$. Outras características dismórficas foram observadas de forma isolada: clinodactilia $(14,3 \%)$, face triangular $(7,1 \%)$, hipo e hipertelorismo $(3,6 \%)$, boca pequena com lábios finos $(10,7 \%)$, pavilhão auricular proeminente $(3,6 \%)$, dedos curtos $(10,7 \%)$, pectus excavatum $(3,6 \%)$, apagamento do filtro nasal $(3,6 \%)$ e úvula bífida $(3,6 \%)$.

A análise das famílias estudadas permite observar que quadros clínicos mais graves estão associados a genótipos de mutações "nonsense" $(11,15,35)$ e nos casos de mutações em heterozigose composta (11), enquanto pacientes heterozigotos simples para mutações " missen$s e$ ", na maioria das vezes, apresentaram formas clínicas mais leves, de difícil identificação. Essa grande variabilidade quanto a gravidade de retardo de crescimento pré- e pós-natal e à presença de características dismórficas e do comprometimento cognitivo dos indivíduos das sete famílias com a mutação do IGFIR pode refletir um espectro da atividade remanescente da sinalização do IGF-1 (12,32). Pode-se concluir, dessa forma, que o quadro clínico é compatível com o número de alelos funcionantes do IGF1R, corroborando a condição de herança autossômica dominante com fenótipo ou expressividade variável.

Laboratorialmente esses pacientes apresentam grande variabilidade nas concentrações de IGF-1, que va- 
riaram de valores normais a discretamente elevados, enquanto os valores de IGFBP-3 encontram-se dentro dos limites da normalidade em praticamente todos os pacientes avaliados (Tabela 2). A secreção de $\mathrm{GH}$, avaliada por testes de estímulo, permite afastar deficiência de $\mathrm{GH}$, porém poucos pacientes apresentam valores nitidamente elevados desse hormônio $(11,16,32)$.

Diferente do observado em pacientes com defeitos no IGFI, que apresentam resistência à insulina evidente $(9,39)$, poucos pacientes com mutações no IGFIR exibiram diferentes graus de alteração no metabolismo de carboidrato: uma paciente de 35 anos com discreta resistência à insulina (9) e quatro familiares, em que três apresentavam intolerância oral à glicose e um com histórico de diabetes gestacional (35). Permanece obscuro o mecanismo pelo qual as mutações no IGFIR levam à interferência no metabolismo dos carboidratos, entretanto existem evidências que sugerem a associação entre ter nascido pequeno para a idade gestacional e apresentar reduzida função de células $\beta$ pancreáticas $(40,41)$. Por outro lado, estudos in vitro que avaliaram a resposta à insulina de fibroblasto de um paciente com mutação no IGFIR demonstraram que a sua haploinsuficiência leva ao aumento da sensibilidade à insulina. O provável mecanismo desse fenômeno origina-se da diminuição dos receptores híbridos IGF-1R/INSR, os quais não são sensíveis à insulina, em favor do aumento dos halorreceptores de insulina (INSR). Entretanto, essa melhora da sensibilidade insulínica observada in vitro não foi refletida nos testes de tolerância oral à glicose realizada nesses pacientes (15).

\section{RESPOSTA AO TRATAMENTO COM RHGH}

O uso do rhGH para tratamento de crianças nascidas pequenas para a idade gestacional sem recuperação espontânea do crescimento é aprovado pelo FDA (U.S. Food and Drug Administration), na dose de $0,48 \mathrm{mg} /$ $\mathrm{kg}$ /semana, e pela EMEA (European Agency for the Evaluation of Medical Products), que preconiza a dose de $0,22 \mathrm{mg} / \mathrm{kg} /$ semana. O tratamento com rhGH em crianças nascidas SGAs é menos efetivo comparado com os pacientes com deficiência de $\mathrm{GH}$, mesmo com doses de rhGH mais altas e início da terapia com a média da idade mais baixa $(3,4)$.

Das sete crianças com haploinsuficiência do IGFIR, tratadas com o hormônio do crescimento recombinante humano $(\mathrm{rhGH})$, duas apresentaram resposta satisfatória ao tratamento a curto prazo com ganho em $\mathrm{Z}$ de altura de 0,55 e 0,8 após 6 a 12 meses de tratamento $(9,11)$. Cinco outras crianças não obtiveram resposta adequada ao tratamento após um ano de avaliação apesar de altas doses de rhGH utilizada (70 $\mu \mathrm{g} / \mathrm{kg} /$ dia) (Tabela 3$)$. Todos os relatos restringem-se a descrições de tratamento por um pequeno período, não havendo dados quanto à altura final desses pacientes. Dessa forma, não se pode estabelecer um consenso em relação à eficácia do tratamento com rhGH em crianças nascidas SGAs com mutações no IGFIR.

Tabela 3. Revisão da literatura de dados laboratoriais e clínicos dos pacientes nascidos pequenos para a idade gestacional e com mutação no IGF1R que foram tratados com hormônio do crescimento

\begin{tabular}{|c|c|c|c|c|c|c|c|}
\hline $\begin{array}{l}\text { Mutação do IGF1R/ } \\
\text { referência }\end{array}$ & $\begin{array}{c}\text { p.R138Q/K145N } \\
\text { (11) }\end{array}$ & $\begin{array}{l}\text { p.R89X } \\
(11,15)\end{array}$ & $\begin{array}{c}\text { p.E1050K } \\
\text { (16) }\end{array}$ & $\begin{array}{c}\text { p.R511Q } \\
\text { (13) }\end{array}$ & $\begin{array}{c}\text { p.V629E } \\
(33)\end{array}$ & $\begin{array}{l}\text { c.3348_3366 } \\
\text { dup19 } \\
\text { (34) }\end{array}$ & $\begin{array}{r}\text { p.Y387X } \\
\text { (35) }\end{array}$ \\
\hline \multicolumn{8}{|l|}{ Ao nascimento } \\
\hline IG (semanas) & 38 & 38 & 39 & 41 & 40 & 40 & 40 \\
\hline Comprimento (Z) & N.D. & $-5,9$ & -4.2 & -4.9 & -1.9 & $-2,2$ & $-3,0$ \\
\hline Peso (Z) & -4.3 & -3.5 & -3.3 & -3.1 & -2.2 & $-0,6$ & $-2,0$ \\
\hline \multicolumn{8}{|c|}{ No início da terapia com rhGH } \\
\hline Idade (anos) & 4.5 & 6.4 & 1.6 & 13.6 & 7.4 & 9,6 & 8 \\
\hline Altura (Z) & $-4.0^{\mathrm{a}}$ & -2.5 & -2.3 & -5.0 & $-2.0^{\mathrm{a}}$ & $-3,6$ & $-4,5^{a}$ \\
\hline IGF-1 (Z) & normal $^{b}$ & +1.2 & +2.1 & elevado ${ }^{b}$ & +2.2 & normal & $+2,1$ \\
\hline Dose de rhGH ( $\mu \mathrm{g} / \mathrm{Kg} / \mathrm{dia})$ & 53 & 30 & 47 & 70 & $31-36$ & 46 & 37 \\
\hline \multicolumn{8}{|c|}{ Após um ano de terapia com rhGH } \\
\hline Altura (Z) & $-4.0^{\mathrm{a}}$ & -1.9 & $-1.5^{b}$ & $-5.0^{c}$ & -2.1 & $-3,2^{\mathrm{a}}$ & $-4,4^{a}$ \\
\hline IGF-1 (Z) & elevadob & +1.7 & +3.6 & elevado ${ }^{b}$ & +2.4 & elevado ${ }^{b}$ & n.d. \\
\hline
\end{tabular}

N.D.: não disponível. ${ }^{a}$ : estimado pelo gráfico de crescimento. ${ }^{b}:$ dados do $Z$ dos valores séricos não foram informados. ${ }^{c}:$ dados avaliados seis meses após o início do tratamento. 


\section{CONCLUSÃO}

Como muitos pacientes apresentam dados clínicos e laboratoriais pouco alterados, defeitos do IGFIR devem ser suspeitados em casos de crianças nascidas PIGs sem recuperação do crescimento na vida pós-natal, principalmente quando associados a microcefalia, atraso leve no DNPM, valores elevados de IGF-1 e/ou história familiar semelhante sugerindo herança autossômica dominante. Deve-se inicialmente descartar causas conhecidas de RCIU e baixa estatura. Em um futuro próximo, a disponibilidade de estudos de genética molecular deverá auxiliar o reconhecimento desses pacientes na prática clínica. Estudos futuros avaliando maior número de pacientes com defeitos no IGFIR poderão melhor caracterizar o fenótipo desses pacientes e determinar os benefícios da intervenção terapêutica com rhGH nesse subgrupo especial de crianças nascidas PIGs, apontando, dessa forma, opções para evitar possíveis comorbidades ou diminuir esses efeitos.

Agradecimentos: Este trabalho obteve apoio da Fundação de Amparo à Pesquisa do Estado de São Paulo (Fapesp): (05/50144-2 para Luciana Ribeiro Montenegro e 08/57915-2 para Andréa de Castro Leal) e do Conselho Nacional de Desenvolvimento Científico e Tecnológico (CNPq): $n^{\circ} 301477 / 2009$ para Alexander Augusto de Lima Jorge e ${ }^{\circ}$ 300982/2009-7 para Alexander Augusto de Lima Jorge).

Declaração: os autores declaram não haver conflitos de interesse científico neste estudo.

\section{REFERÊNCIAS}

1. Hokken-Koelega AC, De Ridder MA, Lemmen RJ, DenHartog $H$, De MuinckKeizer-Schrama SM, Drop SL. Children born small for gestational age: do they catch up? Pediatr Res. 1995;38(2):267-71.

2. Lee PA, Chernausek SD, Hokken-Koelega AC, Czernichow P. International Small for Gestational Age Advisory Board consensus development conference statement: management of short children born small for gestational age, April 24-October 1, 2001. Pediatrics. 2003;111(6 Pt 1):1253-61.

3. Clayton PE, Cianfarani S, Czernichow P, Johannsson G, Rapaport R, Rogol A. Management of the child born small for gestational age through to adulthood: a consensus statement of the International Societies of Pediatric Endocrinology and the Growth Hormone Research Society. J Clin Endocrinol Metab. 2007;92(3):804-10.

4. Saenger $P$, Czernichow $P$, Hughes I, Reiter EO. Small for gestational age: short stature and beyond. Endocrine reviews. 2007;28(2):219-51.

5. Woods KA, Camacho-Hubner C, Savage MO, Clark AJ. Intrauterine growth retardation and postnatal growth failure associated with deletion of the insulin-like growth factor I gene. N Engl J Med. 1996;335(18):1363-7.

6. Gluckman PD. Clinical review 68: the endocrine regulation of fetal growth in late gestation: the role of insulin-like growth factors. J Clin Endocrinol Metab. 1995;80(4):1047-50.
7. Bonapace G, Concolino D, Formicola S, Strisciuglio P. A novel mutation in a patient with insulin-like growth factor 1 (IGF1) deficiency. J Med Genet. 2003;40(12):913-7.

8. Coutinho DC, Coletta RR, Costa EM, Pachi PR, Boguszewski MC, Damiani D, et al. Polymorphisms identified in the upstream core polyadenylation signal of IGF1 gene exon 6 do not cause pre- and postnatal growth impairment. J Clin Endocrinol Metab. 2007;92(12):4889-92.

9. Walenkamp MJ, Karperien M, Pereira AM, Hilhorst-HofsteeY, van Doorn J, Chen JW, et al. Homozygous and heterozygous expression of a novel insulin-like growth factor-I mutation. J Clin Endocrinol Metab. 2005;90(5):2855-64.

10. Netchine I, Azzi S, Houang M, Seurin D, Perin L, Ricort JM, et al. Partial primary deficiency of insulin-like growth factor (IGF)-I activity associated with IGF1 mutation demonstrates its critical role in growth and brain development. J Clin Endocrinol Metab. 2009;94(10):3913-21.

11. Abuzzahab MJ, Schneider A, Goddard A, Grigorescu F, Lautier $C$, Keller E, et al. IGF-I receptor mutations resulting in intrauterine and postnatal growth retardation. $\mathrm{N}$ Engl $\mathrm{J}$ Med. 2003;349(23):2211-22.

12. Ester WA, van Duyvenvoorde HA, de Wit CC, Broekman AJ, Ruivenkamp CA, Govaerts LC, et al. Two short children born small for gestational age with insulin-like growth factor 1 receptor haploinsufficiency illustrate the heterogeneity of its phenotype. J Clin Endocrinol Metab. 2009;94(12):4717-27.

13. Inagaki K, Tiulpakov A, Rubtsov $P$, Sverdlova P, Peterkova V, Yakar $S$, et al. A familial insulin-like growth factor-l receptor mutant leads to short stature: clinical and biochemical characterization. J Clin Endocrinol Metab. 2007;92(4):1542-8.

14. KawashimaY, Kanzaki S, Yang F, KinoshitaT, Hanaki K, Nagaishi J, et al. Mutation at cleavage site of insulin-like growth factor receptor in a short-stature child born with intrauterine growth retardation. J Clin Endocrinol Metab. 2005;90(8):4679-87.

15. Raile K, Klammt J, Schneider A, Keller A, Laue S, Smith R, et al. Clinical and functional characteristics of the human Arg59Ter insulin-like growth factor i receptor (IGF1R) mutation: implications for a gene dosage effect of the human IGF1R. J Clin Endocrinol Metab. 2006;91(6):2264-71.

16. Walenkamp MJ, van der Kamp HJ, Pereira AM, Kant SG, van Duyvenvoorde HA, Kruithof MF, et al. A variable degree of intrauterine and postnatal growth retardation in a family with a missense mutation in the insulin-like growth factor I receptor. J Clin Endocrinol Metab. 2006;91(8):3062-70.

17. Kruis T, Klammt J, Galli-Tsinopoulou A, Wallborn T, Schlicke M, Muller $E$, et al. Heterozygous mutation within a kinase-conserved motif of the insulin-like growth factor I receptor causes intrauterine and postnatal growth retardation. J Clin Endocrinol Metab. 2010;95(3):1137-42.

18. Wallborn T, Wuller S, Klammt J, Kruis T, Kratzsch J, Schmidt G, et al. A heterozygous mutation of the insulin-like growth factor-I receptor causes retention of the nascent protein in the endoplasmic reticulum and results in intrauterine and postnatal growth retardation. J Clin Endocrinol Metab. 2010;95(5):2316-24.

19. Ward CW, Garrett TP, McKern NM, Lou M, Cosgrove LJ, Sparrow LG, et al. The three dimensional structure of the type I insulin-like growth factor receptor. Mol Pathol. 2001;54(3):125-32.

20. Adams TE, Epa VC, Garrett TP, Ward CW. Structure and function of the type 1 insulin-like growth factor receptor. Cell Mol Life Sci. 2000;57(7):1050-93.

21. Nakae J, Kido Y, Accili D. Distinct and overlapping functions of insulin and IGF-I receptors. Endocrine Rev. 2001;22(6):818-35.

22. Jain S, Golde DW, Bailey R, Geffner ME. Insulin-like growth factor-I resistance. Endocrine Rev. 1998;19(5):625-46. 
23. Dupont J. Insulin and insulin-like growth factor I receptors: similarities and differences in signal transduction. J Horm Res. 2001;55:22-6.

24. Liu JP, Baker J, Perkins AS, Robertson EJ, Efstratiadis A. Mice carrying null mutations of the genes encoding insulin-like growth factor I (Igf-1) and type 1 IGF receptor (Igf1r). Cell. 1993;75(1):59-72.

25. Butler AA, LeRoith D. Minireview: tissue-specific versus generalized gene targeting of the igf1 and igf1 $r$ genes and their roles in insulin-like growth factor physiology. Endocrinology. 2001;142(5):1685-8.

26. Accili D, Drago J, Lee EJ, Johnson MD, Cool MH, Salvatore P, et al. Early neonatal death in mice homozygous for a null allele of the insulin receptor gene. Nat Genet. 1996;12(1):106-9.

27. DeChiara TM, Efstratiadis A, Robertson EJ. A growth-deficiency phenotype in heterozygous mice carrying an insulin-like growth factor II gene disrupted by targeting. Nature. 1990;345(6270):78-80.

28. Duvillie B, Cordonnier N, Deltour L, Dandoy-Dron F, Itier JM, Monthioux $E$, et al. Phenotypic alterations in insulin-deficient mutant mice. Proc Natl Acad Sci U S A. 199713;94(10):5137-40.

29. Joshi RL, Lamothe B, Cordonnier N, Mesbah K, Monthioux E, Jami J, et al. Targeted disruption of the insulin receptor gene in the mouse results in neonatal lethality. Embo J. 1996;15(7):1542-7.

30. Ueki K, Yamauchi T, Tamemoto H, Tobe K, Yamamoto-Honda R, Kaburagi $Y$, et al. Restored insulin-sensitivity in IRS-1-deficient mice treated by adenovirus-mediated gene therapy. J Clin Invest. 2000;105(10):1437-45.

31. Al-Regaiey KA, Masternak MM, Bonkowski M, Sun L, Bartke A. Long-lived growth hormone receptor knockout mice: interaction of reduced IGF-1/insulin signaling and caloric restriction. Endocrinology. 2005;146(2):851-60. Epub 2004 Oct 21.

32. Kruis T, Klammt J, Galli-Tsinopoulou A, Wallborn T, Schlicke M, Muller $E$, et al. Heterozygous mutation within a kinase-conserved motif of the insulin-like growth factor I receptor causes intrauterine and postnatal growth retardation. J Clin Endocrinol Metab. 2010;95(3):1137-42.
33. Wallborn T, Wuller S, Klammt J, Kruis T, Kratzsch J, Schmidt G, et al. A heterozygous mutation of the insulin-like growth factor-I receptor causes retention of the nascent protein in the endoplasmic reticulum and results in intrauterine and postnatal growth retardation. J Clin Endocrinol Metab. 2010;95(5):2316-24.

34. Fang P, Schwartz ID, Johnson BD, Derr MA, Roberts CT Jr, Hwa V, et al. Familial short stature caused by haploinsufficiency of the insulin-like growth factor i receptor due to nonsense-mediated messenger ribonucleic acid decay. J Clin Endocrinol Metab. 2009;94(5):1740-7.

35. Mohn A, Marcovecchio ML, de Giorgis T, Pfaeffle R, Chiarelli F, Kiess W. An insulin-like growth factor-I receptor defect associated with short stature and impaired carbohydrate homeostasis in an Italian pedigree. Horm Res Paediatr. 2011;76(2):136-43.

36. Inagaki k. A Familial insulin-like growth factor-I receptor mutant leads to short stature: clinical and biochemical characterization. J Clin Endocrinol Metab. 2007;92(4):1542-8.

37. Domene HM, Martinez AS, Frystyk J, Bengolea SV, Ropelato MG, Scaglia PA, et al. Normal growth spurt and final height despite low levels of all forms of circulating insulin-like growth factor-I in a patient with acid-labile subunit deficiency. Horm Res. 2007;67(5):243-9.

38. van Nieuwpoort IC, Drent ML. Cognition in the adult with childhood-onset GH deficiency. Eur J Endocrinol. 2008;159/Suppl 1):S53-7.

39. Woods KA, Camacho-Hubner C, Bergman RN, Barter D, Clark AJ, Savage MO. Effects of insulin-like growth factor I (IGF-I) therapy on body composition and insulin resistance in IGF-I gene deletion. J Clin Endocrinol Metab. 2000;85(4):1407-11.

40. Ong KK, Petry CJ, Emmett PM, Sandhu MS, Kiess W, Hales CN, et al. Insulin sensitivity and secretion in normal children related to size at birth, postnatal growth, and plasma insulin-like growth factor-I levels. Diabetologia. 2004;47(6):1064-70.

41. Gluckman PD, Hanson MA, Cooper C, Thornburg KL. Effect of in utero and early-life conditions on adult health and disease. $\mathrm{N}$ Engl J Med. 2008;359(1):61-73. 